\title{
Urostomy: Complications and Impact on Quality of Life
}

\author{
Moussaab Rachid, Mayele. M, Graiouid. M, Allali. S, Doumer. A, Dakir. M, A. Debbagh \\ R. Aboutaieb \\ Ibn Rochd University Hospital, Urology Department, Casablanca, Morocco. \\ moussaaburo@gmail.com
}

\section{Summary}

Introduction: The urostomy applies to any method allowing to derive the urine without physiological continence being maintained or extra-physiological continence system is created, in this case the flow of urine is permanent. It induces a real upheaval in the daily life of the patient with urostomy.

Purpose: Study the various complications of urostomy and to assess their impact on the patients quality of life.

Material and Patients: We report a retrospective study spread over 3 years from February 2015 until February 2018, within the urology department at the Hospital Ibn Rochd of Casablanca , involving 70 patients who had a incontinent urinary diversion with the impact of ureterostomy on the quality of life through the Bladder Cancer Index questionnaire (BCI) that was established in the United States (USA) translated into French and validated then translated into Arabic.

Results: Two types of external derivations have been recommended: Trans-ileal ureterostomy (Bricker): $60 \%$ of cases (42 patients) and cutaneous ureterostomy: $40 \%$ of cases (28 patients). The complications observed depended on the type of diversion, and were distributed as follows: Trans-ileal ureterostomy: 4 cases of pyeloureteral stenosis + pyelo-ureteral dilation, 1 case of releasing stitches of the intestinal anastomosis + peritonitis, 2 cases of urolithiasis + lithiasis at the Bricker level, 4 cases of pyelonephritis, 1 case of peristomal hernia. Direct cutaneous ureterostomy: 1 case of ureterostomy necrosis, 1 case of probe migration, 2 cases of pyelonephritis. Regarding the impact of ureterostomy on the patient's quality of life; we evaluated according to the BCI 3 domains: Urinary domain: preserved with a score of 82.55; Bowel domain: relatively conserved with score 86. Sexual domain: significantly impaired with score 42 and no activity at $64.3 \%$. We note that $89 \%$ of our patients report a normal pursuit of social activities. $75 \%$ of patients accepted their stoma and $64 \%$ were autonomous for stoma care. For the $36 \%$, the care was done by a relative or a health professional.

Conclusion: The urostomy decision is a complex process that aims to provide the best possible quality of life for the patient depending on the context. The ideal derivation should preserve renal function and minimize morbidity.

Keywords: urostomy, complications, impact, life.

\section{INTRODUCTION}

Urostomy applies to any method allowing the urine to be diverted without physiological continence being maintained or without creating an extra - physiological continence system, that is to say that the flow of urine is permanent. A urine collection system, attached to the skin is therefore necessary. Most urostomies are created after cystectomy or sometimes after trauma or neurological disease. Since the mid-19th century, multiple techniques for non-continuous urinary diversion have been proposed. With the progressive abandonment of non-continuous digestive diversions, particularly sigmoid due to metabolic disorders and alteration of the upper 
urinary tract, the two main non-continuous urinary diversions used today are: direct cutaneous ureterostomy and ureterostomy trans-ileal as described by Bricker (1). Wearing a stoma can induce a real upheaval in the daily life of the person concerned; it leads to multiple physical and psychological changes for the patient and his entourage that are inevitable and often difficult to live with. The objective of this work is to study the complications of urostomies and their impact on the life of patients through a survey BCI (Bladder Cancer Index) by evaluating 3 areas: urinary, gastrointestinal and sexual, and then to confront our results with data from the literature.

\section{Materials And Patients}

This is a retrospective study conducted in the urology department of the Ibn Rochd University Hospital in Casablanca on the complications of external urinary diversions with the study of their impact on the patients quality of life (QOL). This study was conducted over a 3-year period from February 2015 to February 2018. Patients were included in the study regardless of age, gender, emergency and co-morbidities. These patients underwent non-continuous urinary diversion. All patients with internal urinary diversion were excluded. Bladder Cancer Index (BCI) is a questionnaire that was developed in the United States (USA) by the University of Michigan's team. It has been translated into French and validated by the Urology Department of the Rouen University Hospital's team (France), then translated into Arabic and validated by the Urology Department B at the Ibn Sina University Hospital in Rabat. The primary result measures the scores of the function and the discomfort of each BCI urinary, gastrointestinal and sexual health domain. The responses to the items are based on the Likert scale, with domain and subdomain scores Standardized to a scale from 0 to 100 points where the highest scores answer to a better quality of life. The cases were collected by an exhaustive search in the files, the registers of the operating reports and the data contained in each file were recorded on an exploitation sheet. We also collected additional data regarding the impact of urostomy on their social life through the Bladder Cancer Index (BCI) by talking to our patients over the phone.

\section{RESULTS}

Our series includes 57 men and 13 women, $82 \%$ men and 18\% women. The average age in our series was 66.91 years with extremes of 42 and 89 years of age. The most affected population is between the ages of 60 and 69 , all sexes combined. The operating indications which required non-continuous urinary diversions were variable and dominated by the malignant pathologies of the bladder, they are summarized in the table 1

Table1. Distribution of cases according to the indication for ureterostomy

\begin{tabular}{|l|c|c|}
\hline Indications & Number & Percentage \% \\
\hline Muscle invasive bladder cancer & 50 & 71,5 \\
\hline Bladder papillomatosis & 15 & 21,5 \\
\hline Hemostasis cystectomy & 3 & 4 \\
\hline Endometrial tumor invading the bladder & 1 & 1,5 \\
\hline Mixed superficial bladder tumor with massive epidermal component & 1 & 1,5 \\
\hline
\end{tabular}

In our series, the Bricker type bypass was performed in $60 \%(n=42)$ of patients. The cutaneous ureterostomy was performed in 28 patients. In the 70 cases in our series, $40 \%(n=28)$ received neoadjuvant chemotherapy for muscle invasive bladder tumor. The 3 cases who had undergone a hemostasis cystectomy had undergone failed hemostasis radiotherapy before the cystectomy was decided. For the Complications of urinary stomies: four patients presented uretero-ileal or uretero-Brickerian stenosis associated with pyelo-ureteral dilation, two of whom underwent uretero-brickerian reimplantation after failure of JJ descent. A patient underwent mono 
J descent by flexible anterograde ureteroscopy. A case with peritonitis following the release of the stitches of the digestive anastomosis, the patient had undergone peritoneal lavage and ileostomy. A case of urolithiasis of the excretory tract and a case of lithiasis of the operated bricker. 4 patients presented pyelonephritis after cystoprostatectomy with bricker of which 2 were early and had benefited from a change of the ureteral stent and put on antibiotics and the 2 other cases treated by parenteral antibiotics. One patient presented a peristomal hernia appeared one year after without any real clinical impact. One patient presented with ureterostomy necrosis. The behaviour to have consisted in applying local care while keeping the ureteral catheter in place. Regarding the acceptance of the stoma: $75 \%$ of the patients declared that they were satisfied with their urinary diversion and accepted it, 25\% expressed their dissatisfaction with a feeling of depreciation following their diversion. $64 \%$ of the patients declare themselves autonomous for stoma care, that is 45 patients. $36 \%$ are not, of fear of badly manipulate the stoma. The care is provided for 20 patients by a relative, for the others by a home nurse. The assessment of the quality of life has shown that in $3 / 4$ of the cases, the overall quality of life score is between $50-75$ on a scale 0 to 100 , with an average of 71.85 corresponding to a slightly altered quality of life (p value $<0,20$ ). The Assessment of the areas was as follows:

\section{The Urinary Area}

\section{a. The overall result}

In almost $60 \%$ of the cases in our series, the score relating to the urinary domain is estimated between $50-75$ on a scale of 0 to 100 , with an average of 63 indicating that this domain is significantly conserved ( $p$ value $<0.05$ )

\section{b. The functional result}

In almost $2 / 3$ of the cases, urinary function is estimated between $50-75$ on a scale of 0 to 100 , with an average of 68.5 .

\section{c. discomfort}

In $71.4 \%$, the residual discomfort is estimated between $75-100$ on a scale of 0 to 100 , with an average of 85 . $.28 \%$ of patients report having no urinary leakage during the day.

. In 34\%, a total absence of discomfort caused by the type of urostomy was noted.

$.89 \%$ of patients normally continue their social activities.

\section{The Gastrointestinal Area}

\section{a. The overall result}

In $3 / 4$ of the cases (75\%), the score relating to the gastrointestinal domain is estimated between 75-100 on a scale of 0 to 100 , with an average of 86 ( $p$ value $<0.1$ ) which means that this area is relatively preserved.

\section{b. The functional result}

In almost $2 / 3$ of the cases, the gastrointestinal function is estimated between $75-100$ on a scale of 0 to 100 , with an average of 85 .

\section{c. discomfort}

In $57.14 \%$, the residual discomfort is estimated between $75-100$ on a scale of 0 to 100 , with an average of 93 .

$.25 \%$ of patients report having no episodes of diarrhea.

. A total absence of discomfort when passing a bowel movement has been reported in $50 \%$ of cases. 


\section{Sexual Health Area}

\section{a. The overall result}

In almost half of the cases (48.14\%), the score relating to the sexual domain is estimated between $25-50$ on a scale of 0 to 100 .

The urostomy represents a handicap for the patient's sexual life, with an average score of 42 indicating that sexual health is significantly impaired ( $p$ value $<0.05$ ).

\section{b. The functional result}

In almost $2 / 3$ of the cases (64.3\%), sexual function is estimated between $25-50$ on a scale of 0 to 100 , with an average of 31 .

Respondents reported an absence of sexual activity in $64 \%$ of the cases, more or less associated with a disability in $25 \%$ of the cases.

\section{DisCUSSION}

Urostomy or urinary stoma is the abutment of the urinary tract to the skin either via a tube (ureterostomy) or a segment of the small intestine into which the ureters are delivered (Bricker) or trans-ilateral cutaneous ureterostomy (TICU). Since the beginning of the 90s, the techniques of dissection of the urethra and the conservation of the mechanisms of continence, have improved in men as in women. At the same time, the low pressure tanks are proving their interests and thus giving rise to orthotopic replacement bladders which ensure a better quality of life. The indications for urostomies are numerous, as soon as a lesion of the excretory pathway leads to functional destruction of the organ, a urinary diversion is performed. The lesion can be of different natures: tumor (mainly bladder tumors), Congenital (bladder extrophy), Neurological (spina bifida or multiple sclerosis), Medical (Urinary tuberculosis), Traumatic. There are different types of urinary stomas. The two most common are the cutaneous ureterostomy (CU) and the trans-ileal cutaneous ureterostomy (TICU) called BRICKER. The main complications are uretero-digestive fistulas: They generally occur around the 8th post-operative day, have a poor prognosis and sometimes lead to death. These fistulas can progress to a spontaneous drying up, or require a surgical resumption with a completion of 'a new uretero-ileal anastomosis. These fistulas are more common in patients who had preoperative radiation therapy (2). The Preservation of the ureteral vascularization, a healthy and well vascularized section, the absence of tension in the anastomosis, post-operative drainage of the ureters and extra-peritonization of the graft if possible, are decisive technical points in this capital time that is the uretero-ileal anastomosis (3). Pyelo-ureteral dilation is of very variable frequency ( 0 to $55 \%$ of cases) depending on the series reported and depending on the means used to highlight it (4). Retrograde ileo-ureterography (brickography) is the choice exam that should be practiced in these situations if there is any doubt as to the permeability of the uretero-ileal anastomosis. Stenoses of the ureteroileal anastomosis are the most frequent cause of deterioration of renal function after urinary diversion (5). It appears that the transposition of the ureter threatens its distal vascularization while exposing it to compression in its path between the root of the meso-sigmoid and the pre-vertebral vessels (6). Certain predisposing factors have been identified such as urinary fistulas, urinary tract infections and ureteral ischaemia. The confrontation of two different mucous membranes (ureteral and digestive) and the technical defects also favor the occurrence of this complication (7). Surgical treatment seems more effective than the Endoscopic one, with a success rate greater than $80 \%$ (8). Urinary Lithiasis can be developed in the urinary excretory tract or in the intestinal segment itself. These are generally calcium phosphate or ammoniac magnesium stones (9). Peri-stomial hernias around the stoma most often require surgical recovery, possibly with the placement of a Prosthetic plaque.The infectious complications represent another possible cause of the deterioration of renal function in the long term, a distinction must be made between asymptomatic chronic infections (bacteriuria frequently observed 
in the ileal duct) and real recurrent outbreaks of acute pyelonephritis which would be observed especially with non-refluxing anastomosis, which do not prevent reflux (11).Concerning kidney failure, the fate of the patient renal function is not always known. The number of patients followed beyond 5 years is not much. Kidney failure is more likely to occur if there is a mechanical problem. Hydroelectrolytic disorders apart from kidney failure in the digestive mucosa, reabsorption of Ammonium chloride and a leak of bicarbonate and potassium. The risk is therefore hyperchloremic acidosis. Peristomal skin problems can affect the quality of life. They must be prevented and spotted quickly to avoid their worsening and associated pain. Four causes of complications are to be sought when faced with a skin problem: a poorly positioned stoma, unsuitable equipment, poor quality local care especially because of the use of irritating products, or products that decrease adhesiveness,care is done with lukewarm water and neutral soap, insufficient or excessive hygiene (12). A stenosis of the stoma is more frequent when the patient is young with a long life expectancy. It causes reflux, poor drainage, infection, and increased pressures which themselves worsen ileo-ureteral reflux. Surgical correction is then necessary. Physically a stoma will cause a big change, and many constraints due to the modification of the functions of evacuation (13). On the psychological level all forms of stomas constitute for the patient a psychological trauma which must be recognized and supported to enable him to overcome this ordeal and recover from a psychological point of view (14).

While cutaneous ureterostomies were frequently performed until the 1950s, this type of diversion has become rare, representing 0.7 to $10 \%$ of the modes of urinary diversion, and is mainly reserved for patients having a palliative cystectomy or when their general condition and their co-morbidities do not allow another mode of derivation. Thus Malavaud et al. (15) showed that this mode of derivation was to be preferred when the ASA score was higher than 3 , thus avoiding the morbidity linked to the use of an ileal segment. The decrease in the number of embodiments of this type of bypass is mainly linked to the need for a device with a permanent ureteral tube which must be changed regularly due to a high risk of ureteral stenosis, in particular at the transparietal passage. The Bricker transileal cutaneous ureterostomy is the current standard technique. It is associated with a low but significant rate of per and postoperative complications (16). In our study series, 42 patients underwent a Bricker type tansileal ureterostomy and 28 patients underwent a simple cutaneous ureterostomy (40\%). In the light of the results reported in the literature, it is difficult to objectively study the complications of transileal cutaneous stomies and cutaneous ureterostomies. Indeed, the series are very heterogeneous in terms of number of patients, operating indications and in the way they report and analyze their complications. Analysis of our results revealed that 16 patients presented complications following their urostomy, wich is $23 \%$. In the overall assessment of morbidities, continence and quality of life when we review the literature, Lee et al. show the feasibility of 2 urinary diversion techniques (continent and non-continent). The main advantage of ureterostomy, apart from the speed and simplicity, is to remain extraperitoneal, without intestinal opening and thus to be well supported by patients, even in poor general condition. It most often requires a double apparatus with both ureterostomy probes which must be changed every 6 to 8 weeks and also a system of collecting bags; it is therefore potentially more easily the source of infectious complications. According to the series published in the literature, the drawbacks of this method are dominated by the risk of the occurrence of two complications, almost permanent urinary tract infection with chronic pyelonephritis and stenosis of the subcutaneous route, a fairly frequent and severe complication requiring difficult surgery. This complication is prevented by the placement of ureteral catheters (17). In our study; out of 28 patients with cutaneous ureterostomies: 4 presented complications (14\%); among which there are 2 cases of acute pyelonephritis, 1 case of ureterostomy stenosis and a migration of probe. In general, cutaneous ureterostomy is considered as a serious mutilation and it is hardly experienced by the patient. But it is still indicated in the event of deterioration of the general state pushing to shorten the operating time. For the trans-ileal cutaneous stomy (Bricker), the essential complication, in addition to stenosis of the stoma and infectious episodes, is the stenosis of uretero-ileal anastomoses, requiring endoscopic or open treatment (18).TSUJI (19), in his study notes an anastomotic ureteral stenosis rate of $18 \%$. 
Stenosis of the uretero-ileal anastomosis is the most common cause of deterioration of renal function after urinary diversion (20), complicating $1.5 \%$ to $18.4 \%$ of the anastomosis performed ( $10 \%$ of cases of ureterostomy Bricker type in our series), and would be more frequent if an anti-reflux process is used. Indeed, it appears that the transposition of the ureter threatens its distal vascularization while exposing it to compression in its path between the root of the meso-sigmoid and the pre-vertebral vessels (21). Certain predisposing factors have been identified such as urinary fistulas, urinary tract infections and ureteral ischemia. The confrontation of two different mucous membranes (ureteral and digestive) and the technical defects also favor the occurrence of this complication. in a neoplasic context. Surgical treatment seems more effective than endoscopic treatment with a success rate of more than $80 \%$. However, the aggressiveness of open surgery has prompted more and more teams to propose an endourological treatment of these stenosis as first line. The current endoscopic possibilities are numerous: single or double J probes, balloon dilation, section with cold blade or laser. The success rates of balloon dilation are overall $50-60 \%$. The success rates of the endoscopic section are overall 40-80\% (23).

Infectious complications are another possible cause of long-term deterioration in kidney function. A distinction must be made between asymptomatic chronic infections (bacteriuria frequently observed in the ileal duct) and real recurrent outbreaks of acute pyelonephritis. Ileal-ureteral reflux which facilitates an ascending infection is of course the most frequently mentioned cause (24). For some, ileo-ureteral reflux only exists if the ileal duct does not drain well, especially when using loops that are too long. In trans-ileal cutaneous stomy, a good quality fitting should serve as a peristaltic duct and not as an inert reservoir (25) .For this reason, it is theoretically useless to make an anti-reflux device for uretero-implantation. stenosis is more to be feared than reflux. In reality, there is probably no perfect technique, the number of techniques described are a proof of this. Met Kilciler notes in a series of 67 cases with trans-ileal ureterostomy 4 cases of acute pyelonephritis. In our series, 4 cases presented pyelonephritis of which 2 were early and benefited from a change in the ureteral catheters and put on antibiotics.

The rates of urolithiasis reported in the literature vary from $0.8 \%$ to $4.7 \%$ ( $4 \%$ in our series). Lithiasis can develop in the urinary excretory pathway or in the intestinal segment itself. These are usually calcium phosphate or ammonia-magnesium stones. Most often, lithiasis is favored by stasis and infection, promoting the development of urease germs in the collector's alkaline urine. However, they may be related to metabolic abnormalities and in particular to hypercalciuria caused by the excessive elimination of bicarbonates in the wall of the intestinal graft (25). Their treatment is above all preventive. In our study, urolithiasis with caliceal location was observed in 2 patients.

Postoperative peritonitis is serious. In the STUDER series (26), the latter described 3 cases of postoperative peritonitis (3\%), 2 of which leaded to death. BENCHEKROUN (27); note in his study 2 cases of peritonitis (1\%) by the digestive anastomosis dropping stitches. One case of postoperative peritonitis in our series was noted (1\%) following the dropping of the stitches of the digestive anastomosis.

Peri-stomial hernias most often require a revision surgery, possibly with the placement of a prosthetic plate. Transposition of the stoma site is sometimes necessary. Their surgical correction can be difficult and must be careful in order to respect the vascularization of the ileal loop. In our series, only one case of peristomal hernia appeared 1 year after ureterostomy, 2\%.

Loss of continence can be seen in many patients as a sign of regression. It takes time to accept and learn the right moves. $75 \%$ of the patients in our study accept their stoma and try to adapt a new way of life, while $25 \%$ are not. Bjerre et al. objectifying that $71 \%$ of the cases in their series accepted their urostomy (28). Simmons et al. draw on various works to define terms "adaptation" and acceptance ":

-adaptation to the stoma concerns "the impact of the stoma, on one hand, on the psychological experience, the social and sexual functioning of the patient and, on the other hand, on the patient's perceptions of it". 
Urostomy: Complications and Impact on Quality of Life

-the acceptance of the stoma is defined as "the acceptance of the limits imposed by surgery without perceiving a negative feeling."

The help and support of the immediate entourage, the family, the spouse are factors that profoundly influence his ability to adapt to his new image and accept his stoma (29).

For the stoma care: $64 \%$ of patients declare themselves autonomous for stoma care while $36 \%$ are not and it is performed either by a relative or by a home nurse. The practice of self-care is very important in adapting the patient to the stoma. He must be able to empty his pocket, change his equipment and treat the stoma. The role of care education is therefore essential. Lazarus and Folkman (30) noted, that learning self-care can only begin if the patient accepts their new body image. This is manifested by watching and talking about the stoma, touching the pocket, letting the stoma be seen by the spouse or someone close to them, etc. Chaudhri et al(37), in their study, observed the adaptation of patients to their stoma when they receive, before the operation, informations concerning their operation, details on the different types of pouch and how to change them. Thus, the authors find that patients have greater self-confidence in the performance of manipulations and care of their stoma when they have been informed. In addition, patients who have previously had interactions with an stomatherapist adapt better, psychologically, to the various changes brought by the placement of a stoma (28).

The original BCI questionnaire was developed by Gilbert and al, in three successive phases. The first consisted of a review of the literature, the second in the development of the questionnaire and the third in its validation. This has gone through the usual stages of assessing consistency and reproducibility. It was done in 315 patients treated at the University of Michigan in 2004 with a bladder tumor.

Its use in our study has made it possible to objectify that urostomies have a significant impact on the quality of the daily life of patients in 3 areas of the $\mathrm{BCI}$, which is consistent with the data in the literature. In our series, the overall quality of life score is 71.85 , corresponding to a slightly altered quality of life $(\mathrm{p}<0.20)$.

With an average score of 63, the urinary domain is preserved in terms of function (68.5) and particularly by the absence of discomfort(85) and this in a significant way $(\mathrm{p}<0.05)$. In view of the published series concerning the urinary domain; in an American study (30), Gilbert reported a score varying between 49.8 and 86.5 for urinary function and a discomfort score between 86.3 and 88.4.

In our series, $28 \%$ of patients declared that they had no urinary leakage during the day, comparable to the study by N. MOTTET (31) objectifying that $20 \%$ of patients presented urinary leakage when their fear of it was more frequent $(78.2 \%)$. The leaks mainly come from the equipment. Their prevention requires a perfect positioning and realization of the stoma as precise as possible and repeated education of the patients. In our study, the total absence of discomfort caused by ureterostomy is reported in 34\% of cases while $66 \%$ presents discomfort in different degrees (minimal, moderate and significant), the pursuit of social activities in $89 \%$ of cases, physical exercise in $34.5 \%$ of cases. This is consistent in certain points with the study by F. Chaouchi (32) objectifying that $62 \%$ of patients who were active before the intervention stopped working after the establishment of an external urinary diversion, caused by the large discomfort felt in the workplace.

The gastrointestinal tract is relatively conserved, recording a score of 86, with gastrointestinal function and residual discomfort scored at 85 and 93 respectively (p "0.10). In our series, $25 \%$ of patients report having no episodes of diarrhea. In $50 \%$ of cases, no difficulty in having a bowel movement is reported. The study by $\mathrm{N}$. MOTTET (31), carried out on 738 cases with Bricker, revealed $49.8 \%$ having presented transit disorders with $18.5 \%$ having diarrhea.

Several recent series have been interested in the sexual problem because it is an integral part of the patient's postoperative comfort. In our series, the sexual function is significantly altered, with a score of 42 (p " 0.05$)$ and a sexual function scored at 31. Similar findings were established by Stefanie Shmidt (33) in his Spanish study; 
a sexual function at 31.2 according to BCI. In our study, we reported an absence of sexual activity in $64.3 \%$ of cases, more or less associated with a disability in $25 \%$ of cases. This is similar to the study by C. CASTAGNOLA (34) which found that most patients believed that their sexual activity had been disturbed after surgery. The same is true for the study by F. CHAOUCHI objectifying that $89 \%$ of patients reported that their sexual life was greatly disturbed with an impact on their married life in $85 \%$ of the cases. Morris (50) has shown that to have a better quality of postoperative life, the patient must have participated in the decision of the type of urinary diversion chosen.

According to the results that we have just presented, we have the final conviction that urostomies do not easily allow the patient's reintegration into social life and that they are a source of psychological problems. Better listening to patients and multidisciplinary management involving urologists, stomatherapists and psychiatrists are important to improve the patient's quality of life postoperatively.

\section{CONCLUSION}

Urostomy is a major urological intervention with complications and a significant impact on the body image as well as on the quality of life. This study allowed us to assess the different complications, our patients tolerance ,as well as its impact on their quality of life by the BCI questionnaire across 3 areas: Urinary, Gastrointestinal and Sexual. By analyzing the results of our study which objectified variable complications of urostomy with repercussions on the daily life of patients, we insist on a careful postoperative follow-up with the importance of stoma care in order to acquire good long-term functional results promoting the quality of our patients adaptation.

\section{REFERENCES}

1. Xavier Gamé. La dérivation urinaire non continente revisitée. Département d'urologie - Transplantation rénale et andrologie - CHU Rangueil - TSA 50032- 31059 Toulouse Cedex 9.

2. Jaffe B.M., Bricker E.M., Butcher H.R.Jr. Surgical complications of ileal segment urinary diversion. Ann. Surg., 1968 ; 167 : 367- 376.

3. Svare J., Walter S., Kristensen J.K., Lund F. Ileal conduit urinary diversion: early and late complications. Eur. Urol., $1985 ; 11: 83-86$.

4. Mejean A., Davody P., Chretien Y., Dufour B. Dérivations urinaires non continentes définitives. Encycl. Méd. Chir. (Elsevier, Paris), Techniques chirurgicales, Urologie- Gynécologie, 41- 213, 1996 ; 10p.

5. Studer U.E; Zingg E. J. Ileal orthotopic bladder substitues : what have learned from 12 years experience with 200 patients. Urol Clin North Am 1997 ; 24 (4): 781- 793.

6. Bretheau D., Ponthieu A., Rossi I., Pasquier J. Surveillance de la fonction rénale par scintigraphie au 99 TcDMSA après urétérostomie cutanée trans- iléale. Prog. Urol., 1991 ; 1 : 871- 879.

7. Parekh, Gilbert, Koch, Josepha. Contient urinary reconstruction verus iléal conduit: a contempory single institution comparison of préoperative morbidity and mortality.

8. Touiti D., Gelet A., Deligne E., Fassi F.H., Benrais N., Martin X., Dubernard J.M. Le traitement des sténoses urétéro- intestinales et urétéro- vésicales par cathéter ballon Acucise®. Prog. Urol., 2001 ; 11 : 12241230.

9. Türkölmez K., Baltaci S., Bedük Y., Gögüs Ç., Gögüs A. A nonrefluxing, serous lined extramural tunnel for ureteroileal anastomosis in ileal conduit urinary diversion : first clinical experience in 10 patients. J. Urol., $2001 ; 166: 898-901$. 
10. Leriche A., Archimbaud J.P., Beydoun S. L'urétérostomie cutanée trans- iléale pré- péritonéale. A propos de 46 observations. J. Urol. (Paris), 1987 ; $93: 341-345$.

11. El Fassi J., Barriol D., Lechevallier E., Ortega J- C., Eghazarian C., Rampal M., Coulange C. Remplacement urétéral par urétéro- iléoplastie isopéristaltique non modelée. Prog. Urol., 2000 ; 10 : 411- 417.

12. Benredjem C., Bourezak C-E., Afif M. Prise en charge des patients stomisés : problématique er réponses apportées par une pharmacie hospitalière. Actualités Pharmaceutiques Hospitalières, Novembre 2010, Vol 24, pp 26-29

13. Convatec Laboratoires : Aide à la prise en charge psychologique du patient stomisé 2005

14. François Haab, Olivier Cussenot, Alain Le Duc. Voies d'abord de l'uretère. EMC Techniques chirurgicales Urologie 1995 :1- 0 [Article 41-110].

15. Malavaud B, Vaessen C, Mouzin M, Rischmann P, Sarramon J, Schulman C. Complications for radical cystectomy. Impact of the American Society of Anesthesiologists score. Eur Urol 2001;39:79-84.

16. Szymanski KM, St-Cyr D, Alam T, Kassouf W. External stoma and peristomal complications following radical cystectomy and ileal conduit diversion: a systematic review. Ostomy Wound Manage 2010; 56: 28-35.

17. Osterlink W ,Lobel B, Jajseg, Malmastrone P.U Guideline on bladder cancer. Assoc Eur Urol (eau) Genève 2001

18. Studer U.E; Zingg E. J. Ileal orthotopic bladder substitues : what have learned from 12 years experience with 200 patients. Urol Clin North Am 1997 ; 24, 4: 781- 793.

19. Tsuji, Nakamura, Ariyoshi. Transitional cell carcinoma of the urethra in new followi,g cystectomy for bladder: multivariate analysis for risk factors.

20. Retheau D., Ponthieu A., Rossi I., Pasquier J. Surveillance de la fonction rénale par scintigraphie au 99 TcDMSA après urétérostomie cutanée trans- iléale. Prog. Urol., 1991 ; 1 : 871- 879.

21. Grasset D., Navratil H., Guiter J., Averous M. L'urétérostomie cutanée trans- intestinale. Ann. Urol. (Paris), 1987 ; 21 : 61- 64 .

22. Touiti D., Gelet A., Deligne E., Fassi F.H., Benrais N., Martin X., Dubernard J.M. Le traitement des sténoses urétéro- intestinales et urétéro- vésicales par cathéter ballon Acucise®. Prog. Urol., $2001 ; 11$ : 12241230.

23. Wolf J.S.Jr., Elashry O.M., Clayman R.V. Long- term results of endoureterotomy for benign ureteral and ureteroenteric strictures. J. Urol., 1997; 158 : $759-764$.

24. Mejean A., Davody P., Chretien Y., Dufour B. Dérivations urinaires non continentes définitives. Encycl. Méd. Chir. (Elsevier, Paris), Techniques chirurgicales, Urologie- Gynécologie, 41- 213, 1996 ; 10p.

25. Le Duc A., Camey M., Teillac P. An original antireflux ureteroileal implantation technique : long- term followup. J. Urol., $1987 ; 137: 1156-1158$.

26. Dretler S.P. The pathogenesis of urinary tract calculi occurring after ileal conduit diversion : I. Clinical study. II. Conduit study. III. Prevention. J. Urol., 1973; 109: 204- 209.

27. Studer U. E., Danuser H., Merz V. W., Springer J. P. , Zingg E. J. Experience in 100 patients with an ileal low pressure bladder substitute combined with an afferent tubular isoperistaltic segment. J Urol, 1995, 154: 49-56. 
28. A. Benchekroun, H.A. El Alj, H. Essayegh, A. Iken, Y. Nouini, A. Lachkar, et al. Tumeurs infiltrantes de vessie: étude rétrospective à propos de 225 cas. Annales d'urologie. 2003;37:279-83.

29. C. Feulien B. Crispin A. Deccache Comprendre le vécu des patients stomisés : Quels besoins d'aide et d'éducation

30. Thiercelin L. Le patient stomisé. Thèse de doctorat en Pharmacie. Nantes: Université de Nantes, 2007, $130 \mathrm{p}$

31. Gilbert S.M., Wood D.P., Dunn R.L., Weizer A.Z., Lee C.T., Montie J.E., et al. Measuring health-related quality of life outcomes in bladder cancer patients using the Bladder Cancer Index (BCI). Cancer 2007; 109: 17561762.

32. N.Mottet a, C. Castagnolaa, P. Rischmanna, M. Deixonne, M. Guyot c, P. Colobya, P. Mangina. Qualité de vie après cystectomie : enquête nationale de l'Association française d'urologie (AFU), la Fédération des stomisés de France (FSF) et de l'Association française des entérostomathérapeutes (AFET) chez des patients ayant eu une dérivation urinaire cutanée non continente ou un remplacement vésical orthotopique. Progrès en urologie (2008) 18, 292-298

33. F. Chaouachi , A. Sellami, K. Chaker, K. Mrad Dali , M.A. Ben Chehida , K. Abid, S. Ben Rehouma , Y. Nouira. Qualité de vie après cystectomie avec dérivation urinaire type Briker. Progrès en Urologie ,Volume 27, Issue 13, November 2017, Page 752

34. Schmidt S, Riel R, Frances A, Lorente Garin JA, Bonfill X, Martinez Zapata, Morales Suarez-Varela M, dela Cruz J, Emparanza JI, Sánchez MJ, Zamora J, Goñi JM, Alonso J, Ferrer M1. EMPARO-CU Study Group. Bladder cancer index: cross cultural adaptation into Spanish and psychometric evaluation

35. Castagnola C, Marechal JM, Hanauer MT, Dawahra M, Dubernard JM. Qualité de vie et dérivations urinaires cutanées. Résultats d'un questionnaire adressé à 73 patients. Progrès en Urologie(1996), 6, 207-216

36. Morris J, Ingham R. Choice of surgery for early breast cancer: psychosocial considerations. Soc Sci Med, 1988, 27: 1257- 1262 .

37. Chaudhri S, Brown L, Hassan I, Horgan A F. Preoperative intensive, community-based vs. traditional stoma education: a randomized, controlled trial. Dis Colon Rectum. 2005;48(03):504-509.

Citation: Moussaab Rachid, Mayele. M, et al. "Urostomy: Complications and Impact on Quality of Life". American Research Journal of Urology, 2020; 4(1): 1-10.

Copyright (c) 2020 Moussaab Rachid, Mayele. M, et al. This is an open access article distributed under the Creative Commons Attribution License, which permits unrestricted use, distribution, and reproduction in any medium, provided the original work is properly cited. 